\title{
ОТНОСИТЕЛЬНАЯ РЕАКЦИОННАЯ СПОСОБНОСТЬ МЕТИЛЗАМЕЩЕННЫХ ПРОИЗВОДНЫХ ХЛОРИСТОГО АЛЛИЛА ПРИ КАТИОННОЙ ТЕЛОМЕРИЗАЦИИ С 2-МЕТИЛ-2-БУТЕНОМ
}

Предыдущими исследованиями систем катионной теломеризации выявлен ряд закономерностей в поведении как телогенов, так и таксогенов $\left[{ }^{1-10}\right]$. Изучением сравнительно сложных систем теломеризации на основе 2-метил-1,3-бутадиена $\left[{ }^{1-5}\right]$ установлены некоторые существенные противоречия с известными представлениями о механизме аналогичных процессов электрофильного присоединения, предложены более подходящие кинетические схемы реакции, построены математические модели для простых систем теломеризации ['] и сотеломеризации [ㄹ. В ряде работ данной серии показано, что основные процессы теломеризации сопровождаются протеканием таких побочных реакций, как гомотеломеризация $\left[{ }^{4}\right]$, циклизация $\left[{ }^{4,6-8}\right]$, изомеризация телогенов, таксогенов и промежуточных реакционных комплексов $\left[{ }^{3,6-8}\right]$, теломеризация образующихся продуктов реакции [ $\left.{ }^{5,9}\right]$, перераспределение галогеноводорода между исходными и образующимися продуктами $\left[{ }^{10}\right]$. С помощью построенных математических моделей перечисленные побочные реакции не поддаются удовлетворительному количественному описанию, поскольку механизм их действия пока не раскрыт. Это, в свою очередь, снижает достоверность значений онределяемых кинетических констант теломеризации.

В настоящей работе для сведения влияния перечисленных побочных реакций до минимума в качестве эталонного таксогена был избран 2-метил-2-бутен (I). Реакции этого алкена достаточно хорошо изучены, что позволяет предугадать его поведение в системах катионной теломеризации [ $\left.{ }^{10-12}\right]$. Алкен I обладает высокой таксогенной активностью, малой относительной скоростью роста цепи, в условиях теломеризации не подвергается изомеризации. Чтобы получить правдоподобные количественные данные о реакционной способности аллильных галогенопроизводных, а также о влиянии их химического строения на телогенную активность, нами были использованы в качестве телогенов кинетически равновесные смеси 1-хлор-3-метил-2-бутена с 3-хлор-3-метил1-бутеном (в соотношении 9:1 [3]) (II), 2-хлор-4-метил-3-пентена с $E$-2-хлор-2-метил-3-пентеном (3:1 [ [10]) (III) и $E$-2-хлор-3-нентен (IV). Указанные аллильные хлорпроизводные обладают достаточной телогенной активностью [10], снижающей влияние побочных процессов, и различаются между собой только расположением и количеством метильных заместителей. Кроме того, к алкену I они присоединяются только в наименее замещенном положении аллильной системы молекулы телогена, В качестве моноаддуктов телоген II дает 2-хлор-2,3,6триметил-5-гептен (V), телоген III - 2-хлор-2,3,4,6-тетраметил-5-гептен (VI) и телоген IV - E-2-хлор-2,3,4-триметил-5-гептен (VII) [ $\left.{ }^{10-12}\right]$ 
Исходные и образующиеся продукты, а также их относительные кинетические константы

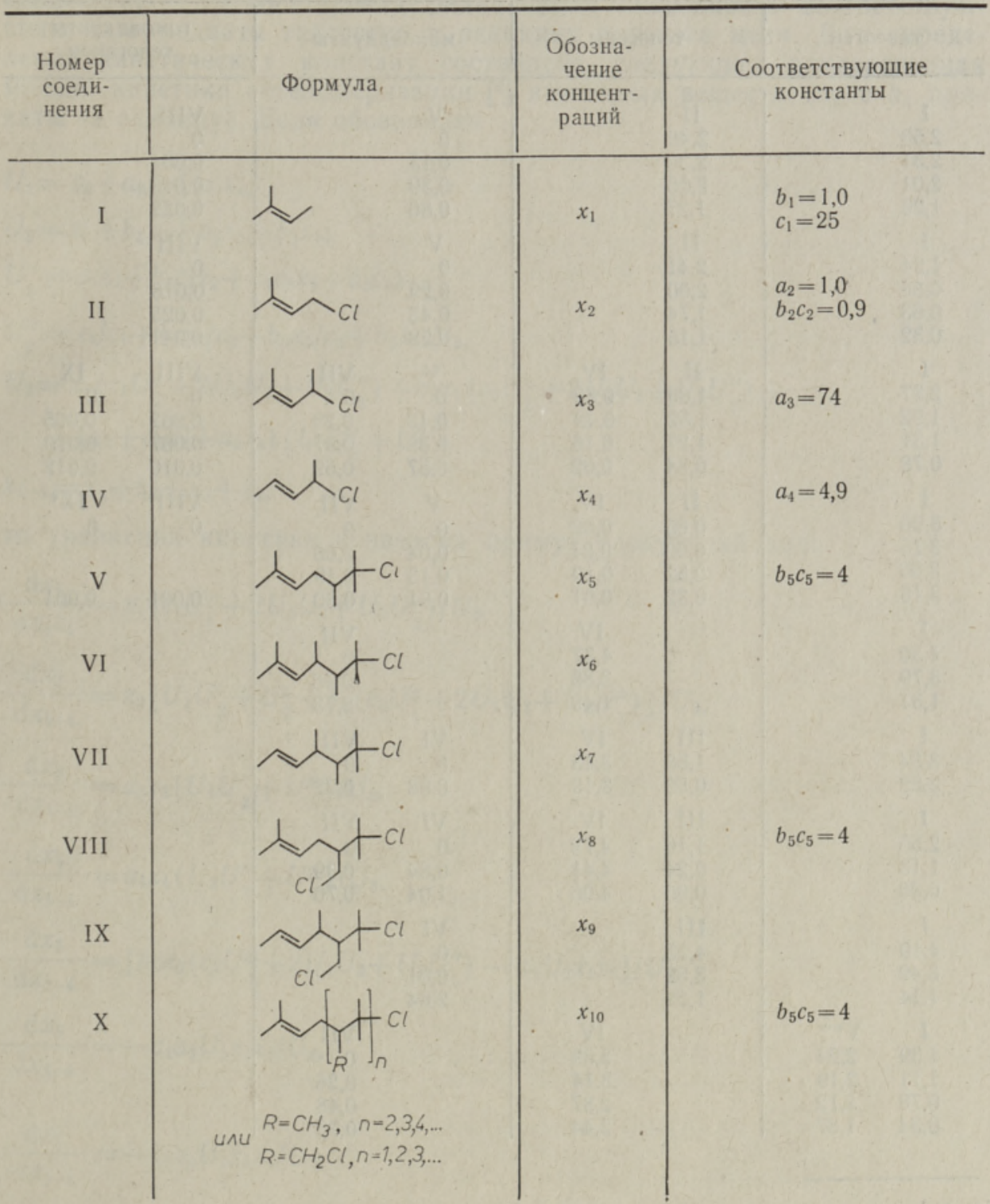

(табл. 1). Атомы галогена образующихся аддуктов в данных системах телогенной активностью не обладают [13]. Как показали предварительные исследования, таксогенную активность в изученных условиях реакции проявляет только аддукт V. Это было установлено на основе определения состава продуктов сотеломеризации V и I c IV. По-видимому, 4-метильные группы, находящиеся в $\beta$-положении к двойной связи образующихся моноаддуктов VI и VII, блокируют их таксогенную активность. Из исходных непредельных телогенов таксогенной активностью обладает хлорид II, дающий гомоаддукты, в том числе 2-хлор-3-хлорметил-2,6-диметил-5-гептен (VIII), а с телогеном IV - 
Изменение концентрации компонентов при теломеризации

\begin{tabular}{|c|c|c|c|c|c|c|c|}
\hline \multicolumn{4}{|c|}{ Исходные реагенты } & \multicolumn{4}{|c|}{ Низшие аддукты } \\
\hline \multicolumn{2}{|c|}{ таксоген } & \multicolumn{2}{|c|}{ телогены } & \multicolumn{2}{|c|}{ моноаддукты } & \multicolumn{2}{|c|}{$\begin{array}{c}\text { гомоаддукты } \\
\text { телогенов }\end{array}$} \\
\hline $\begin{array}{c}\text { I } \\
2,50 \\
2,31 \\
2,01 \\
1,29\end{array}$ & & $\begin{array}{c}\text { II } \\
2,46 \\
2,30 \\
2,00 \\
1,27\end{array}$ & & $\begin{array}{l}\mathrm{V} \\
0 \\
0,13 \\
0,39 \\
0,86\end{array}$ & & $\begin{array}{l}\text { VIII } \\
0 \\
0,004 \\
0,018 \\
0,022\end{array}$ & \\
\hline $\begin{array}{c}\mathrm{I} \\
1,24 \\
0,86 \\
0,63 \\
0,32\end{array}$ & & $\begin{array}{l}\text { II } \\
2,41 \\
2,00 \\
1,74 \\
1,15\end{array}$ & & $\begin{array}{l}\mathrm{V} \\
0 \\
0,29 \\
0,43 \\
0,58\end{array}$ & & $\begin{array}{l}\text { VIII } \\
0 \\
0,018 \\
0,025 \\
0,041\end{array}$ & \\
\hline $\begin{array}{c}\mathrm{I} \\
2,37 \\
1,92 \\
1,31 \\
0,78\end{array}$ & & $\begin{array}{l}\text { II } \\
1,66 \\
1,52 \\
1,27 \\
0,84\end{array}$ & $\begin{array}{l}\text { IV } \\
0,83 \\
0,49 \\
0,16 \\
0,02\end{array}$ & $\begin{array}{l}\text { V } \\
0 \\
0,13 \\
0,38 \\
0,57\end{array}$ & $\begin{array}{l}\text { VII } \\
0 \\
0,29 \\
0,57 \\
0,69\end{array}$ & $\begin{array}{l}\text { VIII } \\
0 \\
0,002 \\
0,007 \\
0,010\end{array}$ & $\begin{array}{l}\text { IX } \\
0 \\
0,005 \\
0,010 \\
0,012\end{array}$ \\
\hline $\begin{array}{c}\text { I } \\
3,90 \\
3,75 \\
3,50 \\
3,15\end{array}$ & & $\begin{array}{l}\text { II } \\
0,65 \\
0,60 \\
0,52 \\
0,32\end{array}$ & $\begin{array}{c}\text { IV } \\
0,32 \\
0,21 \\
0,10 \\
0,01\end{array}$ & $\begin{array}{l}\mathrm{V} \\
0 \\
0,04 \\
0,13 \\
0,31\end{array}$ & $\begin{array}{l}\text { VII } \\
0 \\
0,08 \\
0,19 \\
0,30\end{array}$ & $\begin{array}{l}\text { VIII* } \\
0 \\
0,001\end{array}$ & $\begin{array}{l}0^{\mathrm{IX}^{*}} \\
0,001\end{array}$ \\
\hline $\begin{array}{c}\text { I } \\
4,30 \\
3,79 \\
1,31\end{array}$ & & & $\begin{array}{c}\text { IV } \\
4,37 \\
3,88 \\
1,49\end{array}$ & & $\begin{array}{l}\text { VII } \\
0 \\
0,48 \\
2,73\end{array}$ & & \\
\hline $\begin{array}{c}\text { I } \\
3,54 \\
2,22\end{array}$ & & $\begin{array}{l}\text { III } \\
1,58 \\
0,59\end{array}$ & $\begin{array}{c}\text { IV } \\
3,43 \\
3,19\end{array}$ & $\begin{array}{l}\text { VI } \\
0 \\
0,98\end{array}$ & $\begin{array}{l}\text { VII } \\
0 \\
0,22\end{array}$ & & \\
\hline $\begin{array}{c}\text { I } \\
2,55 \\
1,13 \\
0,36\end{array}$ & & $\begin{array}{l}\text { III } \\
1,16 \\
0,24 \\
0,06\end{array}$ & $\begin{array}{l}\text { IV } \\
4,78 \\
4,41 \\
4,06\end{array}$ & $\begin{array}{l}\text { VI } \\
0 \\
0,84 \\
1,04\end{array}$ & $\begin{array}{l}\text { VII } \\
0 \\
0,39 \\
0,76\end{array}$ & & \\
\hline $\begin{array}{c}\text { I } \\
4,19 \\
3,49 \\
1,14\end{array}$ & & $\begin{array}{l}\text { III } \\
4,15 \\
3,52 \\
1,29\end{array}$ & & $\begin{array}{l}\text { VI } \\
0 \\
0,61 \\
2,64\end{array}$ & & & \\
\hline $\begin{array}{c}\mathrm{I} \\
1,39 \\
1,11 \\
0,78 \\
0,34\end{array}$ & $\begin{array}{l}\mathrm{V}^{* * *} \\
2,24 \\
2,19 \\
2,12 \\
1,87\end{array}$ & & $\begin{array}{c}\text { IV } \\
3,39 \\
3,14 \\
2,87 \\
2,44\end{array}$ & & $\begin{array}{l}\text { VII } \\
0 \\
0,26 \\
0,48 \\
0,95\end{array}$ & & \\
\hline
\end{tabular}

* Количества димеров телогенов VIII и IX определить не удалось.

** Соединение V реагирует в качестве таксогена. Концентрация образующегося аддукта не определялась.

E-2-хлор-3-хлорметил-2,4-диметил-5-гептен (IX) [10]. Из последних только гомоаддукт VIII обладает таксогенной активностью, моделируемой активностью таксогенной связи моноаддукта V.

Относительные реакционные способности телогенов в подобранной системе повышаются в последовательности III $>$ IV $>$ II, таксогенов в последовательности I $>$ V (VIII, X) $>$ II. Исходя из приведенных сведений, для определения относительных констант теломеризации был составлен план опытов сотеломеризации (табл. 2). Согласно [리, дан- 
ная система теломеризации определяется 9-ю относительными константами (табл. 1): $a_{2}, a_{3}, a_{4}, b_{1}, b_{2}, b_{5}, c_{1}, c_{2}, c_{5}$, где $a_{i}$ - относительная реакционная способность телогена в реакциях переноса цепи, $b_{i}-$ относительная реакционная способность таксогена в реакциях роста цепи и $c_{i}$ - относительная реакционная способность соответствующего интермедиата таксогена в реакциях переноса цепи. Для определения кинетических констант составлена следующая конверсионная модель кинетики сотеломеризации [2] изученных веществ $\left(a_{2}\right.$ и $b_{1}$ приняты за единицу). Если обозначить

$$
\begin{aligned}
U_{1} & =x_{2}+a_{3} x_{3}+a_{4} x_{4}, \\
U_{2} & =x_{1}+b_{2} x_{2}+b_{5} x_{5}+b_{5} x_{10}, \\
U_{2}^{\prime} & =c_{1} x_{1}+b_{2} c_{2} x_{2}+b_{5} c_{5} x_{5}+b_{5} c_{5} x_{10}, \\
U_{2}^{\prime \prime} & =x_{1} / c_{1}+b_{2} x_{2} / c_{2}+b_{5} x_{5} / c_{5}+b_{5} x_{10} / c_{5}, \\
U_{3} & =x_{1}\left(c_{1} U_{1}^{2}+2 U_{1} U_{2}+U_{2} U_{2}^{\prime \prime}\right)+b_{2} x_{2}\left(c_{2} U_{1}^{2}+2 U_{1} U_{2}+U_{2} U_{2}^{\prime \prime}\right)+ \\
& +\left(x_{2}+a_{3} x_{3}+a_{4} x_{4}\right)\left(U_{1} U_{2}^{\prime}+U_{2}^{2}\right), \\
x_{1-4} & =x_{1}+x_{2}+x_{3}+x_{4},
\end{aligned}
$$

то уравнения кинетики конверсии примут следующий вид:

$$
\begin{aligned}
& \frac{\mathrm{d} x_{1}}{\mathrm{~d} x_{1-4}}=x_{1}\left(c_{1} U_{1}^{2}+2 U_{1} U_{2}+U_{2} U_{2}^{\prime \prime}\right) / U_{3}, \\
& \frac{\mathrm{d} x_{2}}{\mathrm{~d} x_{1-4}}=x_{2}\left[U_{1} U_{2}^{\prime}+U_{2}^{2}+b_{2}\left(c_{2} U_{1}^{2}+2 U_{1} U_{2}+U_{2} U_{2}^{\prime \prime}\right)\right] / U_{3}, \\
& \frac{\mathrm{d} x_{3}}{\mathrm{~d} x_{1-4}}=a_{3} x_{3}\left(U_{1} U_{2}^{\prime}+U_{2}^{2}\right) / U_{3} \\
& \frac{\mathrm{d} x_{4}}{\mathrm{~d} x_{1-4}}=a_{4} x_{4}\left(U_{1} U_{2}^{\prime}+U_{2}^{2}\right) / U_{3}, \\
& \frac{\mathrm{d} x_{5}}{\mathrm{~d} x_{1-4}}=\left[b_{5} x_{5}\left(c_{5} U_{1}^{2}+2 U_{1} U_{2}+U_{2} U_{2}^{\prime \prime}\right)-c_{1} U_{1} x_{1} x_{2}\right] / U_{3}, \\
& \frac{\mathrm{d} x_{6}}{\mathrm{~d} x_{1-4}}=-c_{1} a_{3} U_{1} x_{1} x_{3} / U_{3}, \\
& \frac{\mathrm{d} x_{7}}{\mathrm{~d} x_{1-4}}=-c_{1} a_{4} U_{1} x_{1} x_{4} / U_{3}, \\
& \frac{\mathrm{d} x_{8}}{\mathrm{~d} x_{1-4}^{\prime}}=\left[b_{5} x_{8}\left(c_{5} U_{1}^{2}+2 U_{1} U_{2}+U_{2} U_{2}^{\prime \prime}\right)-c_{2} b_{2} U_{1} x_{2}^{2}\right] / U_{3} \\
& \frac{\mathrm{d} x_{9}}{\mathrm{~d} x_{1-4}}=-c_{2} b_{2} a_{4} U_{1} x_{2} x_{4} / U_{3}, \\
& \frac{\mathrm{d} x_{10}}{\mathrm{~d} x_{1-4}}=\left[b_{5} x_{10}\left(c_{5} U_{1}^{2}+2 U_{1} U_{2}+U_{2} U_{2}^{\prime \prime}\right)-\left(U_{1} U_{2}^{\prime}-c_{1} U_{1} x_{1}+U_{2}^{2}\right) x_{2}\right] / U_{3} .
\end{aligned}
$$

Расчет значений относительных кинетических констант (табл. 1) проводился на ЭВМ ЕС 1052 аппроксимированием экспериментально 
установленных изменений концентраций исходных веществ и всех низших аддуктов минимизацией суммы

$$
F=\sum_{i=1}^{9} \frac{\left(x_{i}-\bar{x}_{i}\right)^{2}}{\left[\sum_{i=1}^{4}\left(x_{i 0}-x_{i}\right)\right]^{2}}
$$

где $x_{i}$ - опытные, $\bar{x}_{i}-$ расчетные и $x_{i 0}$ - начальные концентрации. Поиск минимума осуществлялся методом Розенброка.

Поскольку относительная активность алкенов определяется главным образом произведением констант $b_{i} c_{i}$ (см. уравнения кинетики), то в случае изучаемой системы теломеризации вычисление констант $b_{2}, c_{2}, b_{5}$ и $c_{5}$ по отдельности не дает точных результатов, так как они непосредственно связаны с трудноопределяемой концентрацией димеpa VIII и с концентрацией высших аддуктов X, которая экспериментально не определялась. Поэтому в табл. 1 приводятся произведения $b_{2} c_{2}$ и $b_{5} c_{5}$.

Полученные значения $a_{i}$ показывают, что переход метильной группы из положения 1 в положение 3 в молекуле аллильного хлорпроиз-

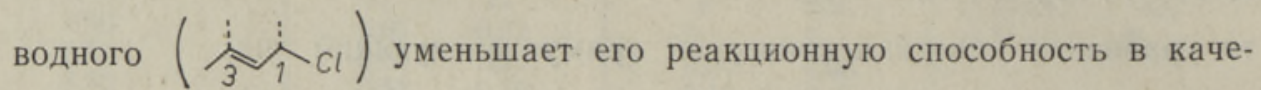

- стве телогена в 4,9 раза; введение дополнительной метильной группы в положение 3 увеличивает его реакционную способность в 15 раз, а в положение 1 - в 74 раза. Это показывает, что значительный вклад в телогенную реакционную способность галогена вносит гиперконъюгация атомов водорода метильных заместителей в положениях 1 и 3 аллильной системы, причем вклад заместителей в положении 1 в два раза больше, чем в положении 3 .

Методики проведения реакции теломеризации, определения состава продуктов и идентификации низших аддуктов описаны в $\left[{ }^{3-5}, 10\right]$.

\section{ЛИТЕРАТУ РА}

1. Лээтс K. В. К изучению ионно-каталитической теломеризации. Х. Математнческая модель катионной теломеризации. - Ж. орган. хим., 1978, 14, № 4, $686-694$

2. Лээтс K. В. K изучению ионно-каталитической теломеризации. XXI. O реакционной способности и химическом строении активированных интермедиатов. Модель кинетики сотеломеризацин. - Ж. орган. хим., 1982, 18, № 10, 20332036.

3. Лээтс K. В., Мукс Э. А. К изучению ионно-каталитической теломеризации. VI. O влиянии строения аллильных изомеров на кинетику и направление реакции. - Ж. орган. хим., 1974, 10, № 2, 162-164.

4. Лээтс K. B., Мукс Э. A. К изучению нонно-каталитической теломеризации. VIII. O влиянии условий реакции на кинетику теломеризации. - Ж. орган. хим., 1974, 10, № 4, 683-687.

5. Лээтc К. В., Мукс Э. А. К изучению ионно-каталитической теломеризацин. IX. О влиянии природы катализатора на состав продуктов и кинетику теломеризации. - Ж. орган. хим., 1974, 10, № 9, 1857-1860.

6. Ранг Х. А., Чернышев В. О., Пехк Т. И., Эрм А. Ю., Лээтс К. В. К изучению ионно-каталитической теломеризации. XVI. Теломеризацня 2-хлор-транс-3-пентена с 2,3-диметил-1-бутеном. - Ж. орган. хим., 1979, 15, № 4, 686-691.

7. Лээтс К. В., Чернышев В. О., Пехк Т. И., Ранг Х. А., Эрм А. Ю. К изучению ионно-каталитической теломеризации. XV. Теломеризация гем.-диалкил- и $\beta$-алкилзамещенных 1-алкенов. - Ж. орган. хнм., 1978, 14, № 5, 913-919. 
8. Чернышев В. О., Пехк Т. И., Ранг Х. А., Лээтс К. В. К изучению ионно-каталитической теломеризации. XIV. Теломеризация 2-хлор-транс-3-пентена с 1-пентеном. - Ж. орган. хим., 1977, 13, № 11, 2300-2304.

9. Mayr, H., Striepe, W. Scope and limitations of aliphatic Friedel-Crafts alkylations. Lewis acid catalyzed addition reactions of alkyl chlorides to carbon-carbon double bonds. - J. Org. Chem., 1983, 48, N 8, 1159-1165.

10. Мукс Э. А., Лээтс K. В. K изучению ионно-каталитической теломеризации XXII. O перераспределении галогеноводорода при теломеризации изоалкенов. - Ж. орган. хим., 1985, 21, № 6, 1177-1180.

11. Лээтс К. В., Чернышев В. О., Ранг Х. А., Эрм А. Ю., Коэль М. Н. О составе продукта теломеризации 1-хлор-3-метил-2-бутена с 2-метил-2-бутеном. Ж. орган. хим., 1975, 11, № 11, 2437.

12. Лээтс K. В., Чернышев В. О., Ранг Х. А., Эрм А. Ю. О составе аддукта 2-хлор3-пентена и 2-метил-2-бутена. - Ж. орган. хим.; 1977, 13, № 8, 1788.

13. Мукс Э. А., Лээтс К. В. О влиянии присутствия 2-хлор-2-метилбутана на теломеризацию 2-метил-1,3-бутадиена с 1-хлор-3-метил-2-бутеном. - Ж. орган. хим., 1980,16 , № 5, 1088-1089.

Ннститут химии

Академии наук Эстонской ССР
Поступила в редакцию $10 /$ XII 1984

\section{K. LÄATS, Elvi MUKS, Lia KRUMM}

\section{METUULASENDATUD ALLOULSETE KLORIIDIDE SUHTELINE REAKTSIOONIVOIME KATIOONSE TELOMERISATSIOONI REAKTSIOONIS 2-METUOL-2-BUTEENIGA}

On uuritud metüülasendatud allüülsete kloriidide telomerisatsiooni ja kotelomerisatsiooni kineetikat 2-metüül-2-buteeniga $\mathrm{SnCl}_{4}$ juuresolekul ning koostatud komponentide suhtelise konversiooni mudel, mille põhjal on arvutatud metüülasendatud allüülsete kloriidide suhtelised aktiivsused antud reaktsioonis.

\section{K. LAATS, Elvi MUKS, Lia KRUMM}

\section{RELATIVE REACTIVITIES OF METHYL-SUBSTITUTED ALLYLIC CHLORIDES IN THE CATIONIC TELOMERIZATION REACTION WITH 2-METHYL-2-BUTENE}

The kinetics of telomerization and cotelomerization of methyl-substituted allylic chlorides with 2-methyl-2-butene in the presence of $\mathrm{SnCl}_{4}$ was studied. A model of the relative kinetics of components was elaborated and the relative rates of methyl-substituted allylic chlorides were calculated. 